\title{
Chapter 13 \\ Synthesis: Conception, Approaches and Strategies for Transformative Change
}

\author{
Maiko Nishi, Suneetha M. Subramanian, Himangana Gupta, \\ Madoka Yoshino, Yasuo Takahashi, Koji Miwa, and Tomoko Takeda
}

\begin{abstract}
This chapter synthesises major findings from the eleven case studies from different countries across the world (i.e. Kenya and Madagascar from Africa; Chinese Taipei, India, Nepal and the Philippines from Asia; Italy, Spain and UK from Europe; Antigua and Barbuda and Colombia from Latin America) concerning SEPLS management in relation to transformative change. It distils key messages in regard to how to understand, assess and take action on transformative change. Implications for science, policy and practice, as well as interfaces between them, are drawn out to address the following questions: (1) what is transformative change? (2) how do we know if we are moving towards a sustainable society? and (3) what are challenges, opportunities and "seeds of change" in the SEPLS context to bring about transformative change? The chapter concludes with five common principles identified across the case studies, while revising the notion of transformative change to reconceptualise it as a radical change that is built on niche innovations of local initiatives and can be fostered through adaptive co-management in the SEPLS context.
\end{abstract}

Contributing authors to this chapter include Jasmine E. Black, Szu-Hung Chen, Emilio Díaz-Varela, Dixon T. Gevaña, Guido Gualandi, Bishnu Hari Pandit, Andrés Quintero-Ángel, Nathalie Viviane Raharilaza, Krishna Gopal Saxena, Ruth Spencer, Chemuku Wekesa, Debra WilliamsGualandi and Chen-Fa Wu.

\footnotetext{
M. Nishi $(\bowtie) \cdot$ H. Gupta

United Nations University Institute for the Advanced Study of Sustainability (UNU-IAS),

Tokyo, Japan

e-mail: nishi@unu.edu
}

\author{
S. M. Subramanian $\cdot$ M. Yoshino \\ United Nations University Institute for the Advanced Study of Sustainability (UNU-IAS), \\ Tokyo, Japan \\ Institute for Global Environmental Strategies (IGES), Hayama, Japan \\ Y. Takahashi $\cdot$ K. Miwa $\cdot$ T. Takeda \\ Institute for Global Environmental Strategies (IGES), Hayama, Japan
}


Keywords Socio-ecological production landscapes and seascapes - Transformative change $\cdot$ Sustainable pathways $\cdot$ Systems approach $\cdot$ Indicators $\cdot$ Landscape governance $\cdot$ Equity $\cdot$ Capacity development

\subsection{Key Messages for Transformative Change in the SEPLS Context}

Building on the case study findings, we first revisit the concept of transformative change to redefine it in the context of SEPLS management. As a way forward in facilitating transformative change, we then suggest approaches and methodologies to be employed for assessing and gauging progress in moving towards a sustainable society. Finally, we explore strategies to bring about transformative change through SEPLS management by examining challenges and opportunities encountered in the process of facilitating and achieving such change.

\subsubsection{What Is Transformative Change?}

While there is a general consensus in policy forums on what positive transformative change entails (IPBES 2019; also refer to Chap. 1 of this volume), pragmatic notions of this concept and how it may be attained are expressed at the level of SEPLS. This is because, at the level of operation, stakeholders focus on optimising human wellbeing and ecological integrity within the landscape or seascape they operate and use resources from and, further, strive to negotiate between local and global priorities of development and sustainability. This means that when 'business as usual' pathways do not seem to provide the desired benefits, actors look for feasible solutions and potential pathways that would enable them to achieve their aspirations. It then becomes an endogenously led, participatory process requiring diverse approaches and capacities towards securing sustainable outcomes that include benefits for the population, economy and for the environment. So, the question that arises is what then constitutes positive transformative change at the level of SEPLS? Based on our experiences, we have characterised transformative change into broad dimensions that may be measured (tangible), and those that are qualitative (intangible), fully acknowledging that there are instances where the boundaries between the two remain fuzzy. Furthermore, it is noteworthy that the tangible and intangible dimensions relate both to social and ecological aspects of the socio-ecological system.

Tangible Dimensions of Transformative Change These refer to aspects that can be physically observed and quantitatively measured. They involve visibly radical changes for the better in practices, approaches, strategies and policy design and implementation relating to the management of SEPLS. Tangible aspects of transformative change could include, for instance: 
- Sustainable use and management of natural resources that includes actions to preserve and enhance biodiversity by increasing cultivated species and a higher likelihood of survival and augmentation of native species. This also includes improvements in landscape design and management, soil and water conservation and other environmental qualities resulting in healthy landscapes and seascapes across multiple environmental services. Further, it includes enabling access to a diversity of resources for food, fuel, health and other well-being requirements. This is a common theme across all the case studies, especially in Chaps. 2, 3, 5, 7, 8 and 9;

- Reduced/avoided wastes (e.g. of food, metals, and plastics; resources) (see for instance Chaps. 6 and 12);

- Increased and diversified sources of income (Chaps. 3, 5, 6 and others);

- Calibrated and integrated development plans that are implemented in an interdisciplinary manner to promote sustainable landscape and seascape management, including restoration and regenerative activities (Chaps. 4, 5, 7, 9 and 11); and

- Reduced and avoided negative trade-offs between different socio-ecological components and functions by encouraging diversity (that allows multiple functions to thrive in the SEPLS) and equitable socio-economic transactions between actors (respectful of plural values that exist amongst the stakeholders).

Intangible Dimensions of Transformative Change These aspects refer to desirable changes in qualitative dimensions relating to the socio-ecological system, and could include, for instance:

- Strong links to individual and collective identities that comprise sense of place, connection to nature, contextually developed agricultural and (innovative) production practices, establishing an emotional and culturally-sensitive affinity to the landscape (see for instance Chaps. 9 and 10).

- Increased awareness, motivations and capacities of local communities, policymakers, and other multiple stakeholders to understand and address unsustainable practices through specific education and knowledge-building activities (Chaps. 3, 5 and 11).

- Improvement in vertical (e.g. between government bodies and communities and their representatives) as well as horizontal (e.g. between community members) communication strategies, efforts and linkages.

- Changes to institutional approaches towards encouraging local/bottom-up contributions and facilitating people-driven processes of landscape management (Chaps. 8 and 9).

- Individual motivations geared towards sustainable practices. This would imply enhanced commitment to priorities related to the diversity and integrity of a landscape and the orientation of cultural values, beliefs and practices towards such transformation (see for instance Chap. 6).

- Anticipatory governance approaches fostered to ensure resilience of socioecological systems. This implies cultivating abilities to quickly respond and adapt to ecological changes, that may include climate disturbances and other 
environmental changes, and to social, economic or political circumstances (Chaps. 4, 5 and 6).

- Development priorities determined in an inclusive, participatory and endogenously led manner by local communities and other bottom-up stakeholders. This implies active multi-stakeholder participation and collaboration at multiple levels, sense of ownership of management outcomes, appreciation of cultural and religious values, and enhancement of knowledge and well-being of communities. It also implies that governance systems focus on designing and implementing policies that mainstream conservation-related activities (including restoration and regeneration of resources and ecosystems) into development, and actively reduce trade-offs between actors and their preferred activities, and consequently also increase equity amongst them (see for instance Chaps. 3 and 9).

Systems Approach Towards Transformative Change Building on the concept of the socio-ecological system, achieving transformative change is possible when activities take cognisance of the interlinkages between social and natural systems at the level of SEPLS. This could include:

- Extending SEPLS planning and management to the three dimensions of sustainable development ${ }^{1}$ including economic (e.g. livelihoods, income, entrepreneurship, and alternative economic models), ecological (e.g. ecological processes, biodiversity, and ecosystem functions) and social (e.g. governance, culture, and property rights).

- Amplifying/increasing synergies between multi-functions of landscapes (sociocultural, economic and ecological) and minimising/managing trade-offs and tensions across local/regional levels of stakeholders and sectors. This will also mean acknowledging and improving the relationship between ecosystems and people. It also implies enhancing ecological connectivity as an essential component of biodiversity conservation.

- Enhanced networks and partnerships between and among stakeholders at multiple levels across different relevant sectors to support local actions (through mobilising financial, political, technical, and other resources).

- Strong inter-generational links that facilitate the transfer of knowledge, skills and wisdom from the elderly to the youth.

\section{Leverage Points that Enable Transitions Towards Transformative Change}

Movements towards desirable states of socio-ecological well-being from an unsustainable one need to be catalysed by several factors. We identify such leverage points of change that can again be characterised as direct and indirect.

1. Shallow leverage points of change have a direct or immediate impact on the process of transformative change. Within the socio-ecological system, these

\footnotetext{
${ }^{1}$ We subscribe to the UN definition of sustainable development, that considers development in a more holistic sense than narrow notions of economic progress.
} 
leverage points could involve biophysical or social dimensions and may include the following interventions:

a. Biophysical

- Sustainable land use policies, plans and programmes that include landscape and seascape restoration efforts (e.g. reforestation, agroforestry, and woodlots);

- Management of invasive species that threatens local biodiversity; and

- Conservation of biological resources (e.g. medicinal plants, native species, wild crop relatives, and good soil), and water and biodiversity management practices (e.g. as a resource for agricultural production, traditional agriculture, integrated pest management, and traditional practices of multiple use of biodiversity).

b. Social

- Broadening awareness on the importance of landscape quality, availability of ecosystem services and need for biodiversity protection-this may involve exercises in long-term visioning of the state of the SEPLS;

- Enhancement of food security (e.g. diverse crops, ecological farming methods, etc. that reduce vulnerabilities to natural and economic shocks);

- Enhancement of health security, through better access to medicinal, nutritional and cultural resources, healthier environment and expertise;

- Enhancement of mitigation and adaptation capacities to deal with natural hazards;

- Enhancement of economic benefits and financial incentives (e.g. for entrepreneurship activities), livelihoods, income, and employment;

- Equitable sharing of economic benefits to ensure that all involved in any economic activity are appropriately compensated for their contributions;

- Clarity of roles and responsibilities in resource management among stakeholders, including sole or co-owned responsibilities (such as between governments and communities);

- Financial, technical and other forms of support for upscaling of best practices;

- Avoiding negative incentives and promoting positive incentives (e.g. eliminating subsidies for chemical fertilisers and promoting multifunctional production processes);

- Promoting investments by private sector in the landscape; and

- Setting up accessible knowledge/learning platforms such as online platforms, webinars, peer-learning visits to landscapes that have transitioned to sustainable production, consumption and well-being, farmers field schools, and local awareness programmes in primary and secondary schools. 
2. Deep leverage points are dimensions that trigger system-wide change and include:

- Re-orienting perceptions of people towards sustainable and equitable production and consumption. This change requires investing in social learning approaches across stakeholder groups that facilitate or mobilise passion towards the landscape and foster linked values of positivity and curiosity, openness, happiness, and cultural pluralism. Furthermore, fostering values such as reciprocity, equilibrium and collectiveness is important to enhance social cohesion and respectful interactions between different stakeholders. This would enable even the private sector to have a re-articulated vision of their roles and responsibilities within the landscape (as seen in Chaps. 7, 9 and 11).

- Economic drivers: While economic drivers are usually considered to directly influence activities in the landscape as they determine production and resource management activities, they can also be related to intangible aspects (e.g. branding, identity, and fostering dimensions of well-being such as health, access to food, education, sense of place that create a sense of pride and value in the production activities and management of the landscape, as seen in Chaps. 6 and 8).

- Sensitive and adequate facilitation by an external or internal agency for community empowerment, capacity development and enabling communications between different players helps to re-articulate priorities within a community. This can foster meaningful public-private partnerships, and coherent communications to collectively identify needs and strategise on ways forward (as illustrated by Chap. 9).

- Effective enforcement by legal and customary institutions that enable reflexive linkages between policymakers and practitioners (as seen in Chap. 10).

- Education, learning and promotion of knowledge systems that help to re-prioritise attitudes of stakeholders. This should include not just formal systems of learning, but experiential pedagogies that enhance sensitisation/ awareness on best practices of SEPLS management and governance. Importantly, a key point to note is that the traditional knowledge related to SEPLS needs to be promoted (as seen in Chaps. 2, 3 and 6).

\subsubsection{How Do We Know If We Are Moving Towards Transformative Change for Sustainability?}

Multi-dimensionality makes the monitoring and evaluation of transformative change as challenging as it is complicated. Monitoring the progress in transformative change, therefore, needs to be structured, keeping in mind the diverse set of indicators which may be specific to a landscape and seascape involving multiple ecosystems. It will help to pick the strongest drivers, frame improvement strategies, 
and explore methods to monitor more qualitative aspects like a community's wellbeing and ethics.

In this section, we discuss various approaches for monitoring and evaluation (M\&E) of transformative change in the context of SEPLS and methods that have been used on the ground to measure it. This helps us capture whether we are really moving towards transformative change. If not, what are the major challenges for M\&E? The approaches emerge directly from the experience of the practitioners of the on-ground projects and initiatives.

Volume 5 of the Satoyama Initiative Thematic Review (SITR-5) clearly highlighted the need for $\mathrm{M} \& \mathrm{E}$ of community-based projects. It also highlighted that the valuation methods should be multi-dimensional and multi-faceted, integrating methodologies where necessary, and drawing from multiple data sources over time to provide more comprehensive assessments and contextual explanations (UNU-IAS and IGES 2019). This also includes identifying key performance indicators/goals and ensuring that the interests of various actors are balanced, and local priorities and international goals are coherent. Here, we describe the steps and methods towards real-time monitoring for SEPLS management from the community lens, promoting their inclusiveness and equal participation in the process.

\section{Monitoring and Evaluation Methods}

Setting up a baseline is a prerequisite for defining evaluation indicators. Depending on the type of project, there could be one baseline representing on-the-ground conditions before the project or two baselines reflecting the current condition and a control condition. Evaluation indicators should take into consideration the projectspecific goals and objectives. This will aid in effective monitoring as the data relevant for the selected indicators will be continuously gathered. The next step, evaluation, helps in assessing the progress in terms of the outputs, outcomes and impacts of the project.

Figure 13.1 shows the detailed steps towards M\&E. M\&E helps improve accountability and increases the capacity of beneficiaries and implementing staff and partners (SOAS 2013). It also helps in identifying the weak areas and tweaking the system to improve the overall performance and outputs. The evaluation is highly dependent on good quality data collection which must take place from setting the baseline stage until the end of the project, continuously or intermittently. The data collection can be done directly with the help of the community or other stakeholders, depending on the chosen approach as described in the following paragraph.

For M\&E, two things must be thought of in the beginning_-processes and tools. The on-the-ground experiences presented in the case studies of this book show that various approaches can potentially ensure long-term M\&E processes (Fig. 13.2), which include: 
Fig. 13.1 Steps towards $\mathrm{M} \& \mathrm{E}$

\section{1 \\ BASELINE SETTING}

- Set a baseline considering current socioeconomic and ecological criteria

- Identify the reference target

\section{DEFINE/ IDENTIFY INDICATORS}

- Identify evaluation indicators

- Consider project/ programme objectives

\section{IDENTIFY SUITABLE APPROACH}

- Process based approach

- Tools based approach

- Participatory / Interdisciplinary / Integrative approach

\section{MONITOR}

- Collect continuous long-term data on the selected indicators

- Ensure scientific robustness

\section{EVALUATE}

- Assess the output, outcome and impact

- Measure quantitative and qualitative change from baselines to assess the effectiveness

\section{INTROSPECT AND ADAPT}

- Identify gaps in implementation

- Tweak the system or adapt for overall improvement in project performance 
Fig. 13.2 Different M\&E approaches in the SEPLS context

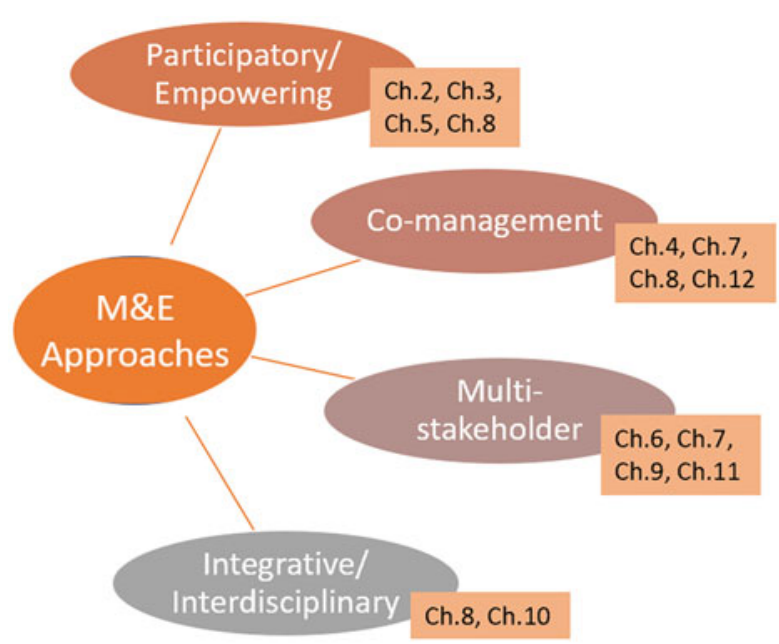

- Participatory and empowering approaches: Local and indigenous communities directly engage in the implementation activities, thereby enhancing their capacities to not only act as the agents of change but also monitor physical progress as they start to understand the baseline and the expected outputs of the intervention. In addition to being able to observe and measure the change based on modern monitoring techniques (e.g. photography, and surveys), they may also use their indigenous knowledge specific to the project area, thereby further enhancing the authenticity of the data collected and the community resilience outcomes of the project. This makes an intervention more sustainable. The data collected directly from the ground is richer and intervention specific. Since the community in this case helps in the successful implementation of the intervention, they can also be motivated to act on the findings. The toolkit "Indicators of Resilience in Socioecological Production Landscapes and Seascapes (SEPLS)" provides tools for engaging local communities in adaptive management (Bergamini et al. 2014).

- Co-management approach: This approach overlaps with the participatory approach, but in this case, not only the implementation and monitoring, but also the planning of the intervention is based on inputs from the community. The community is also a decision-maker and chooses the type of intervention based on its needs, and hence helps in co-managing the project. Community engagement from the initial phase also ensures its long-term commitment to the intervention.

- Integrative and interdisciplinary approaches: From the SEPLS perspective, interdisciplinary approaches are also important as they integrate expertise across different levels and sectors to pursue an integrated assessment of land/seascapes. They may combine biophysical and social knowledge to investigate the interlinkages/relationships for effective evaluation of the outcomes. This may result in co-learning where a community's local and indigenous knowledge can 
be shared in an inter- or transdisciplinary environment, and other stakeholders can pick cues from that to scale up or replicate the model.

- Multi-stakeholder approach: This approach engages several stakeholders and is sometimes considered as one of the best methods, not only for M\&E, but also for achieving the desired goals of the intervention. For this to happen, the needs of different stakeholders and synergy points are identified, on the basis of which their engagement in $M \& E$ processes is ascertained. The stakeholders monitor progress from their own perspectives which can be merged to offer a holistic picture. These stakeholders may also be from interdisciplinary backgrounds offering more insights for the successful implementation of the project.

For most of the above approaches, multi-directional communication is a pre-requisite as it is more holistic involving multiple stakeholders. The most suitable approach for a project will depend on the project site, needs and present capacities of different stakeholders. Once the approach for the M\&E process is decided, tools come next, which are mainly meant to collect data relevant for M\&E. In the context of SEPLS, there are many methods and tools for this process. Tools may vary depending on needs. For example:

- Baseline: Both secondary and primary datasets can be used to determine pre-project conditions, including documents and photos. Secondary data may not reflect on-the-ground real situations and so it is important to check maximum authenticity.

- Measurement of shifts/changes in social norms like community's perception of well-being, qualitative changes in people's livelihoods, fulfilment and enjoyment and connection between people and nature: This can be done by interviews/ surveys, Focus Group Discussions and psychological assessments. This helps in measuring qualitative aspects.

Methods for data collection include:

- Triangulation method: Data may be collected from multiple sources to crossvalidate and enrich findings.

- Artistic methods: These include drawing on socially engaged or participatory arts, photovoice (elicitation of visions through photographs taken and evaluated by local people), and storytelling.

- Technological methods: GIS-based spatial mapping or GPS mapping, and smartphone apps (site specific mobile apps for collecting and archiving the data/information) can be used. A drawback for spatial mapping is that it may miss out on qualitative information. To solve this problem, Public Participatory GIS (PPGIS) can be developed using analogic technologies like printed maps, or 3D landscape models made up from cardboard or clay. Also, qualitative approaches like interviews with stakeholders held on-site while visiting specific locations of the SEPLS may produce spatial-explicit qualitative data (e.g. perceptions, values or even emotions elicited while visiting concrete sites in the SEPLS). 


\section{Challenges in Measuring Progress}

There are many pitfalls in M\&E. When we talk about transformative change, which is a relatively newer term, effective processes need indicators from the transformative angle. Of the tangible and intangible aspects of transformative change (see Sect. 13.1.1), tangible parameters are easier to measure as compared to the intangible ones, as they are more quantifiable. In contrast, intangible ones are difficult to be calibrated as putting values on intangible facets may leave out non-numerical values. In addition, each project/intervention has some site-specific characteristics which demands a more tailor-made M\&E framework across different spatial and temporal scales. This complex, adaptive character in the case of most SEPLS, is a challenge. Any change may cause adaptation of the whole system or some of its specific parts, and implicitly modify reference parameters for "progress". For example, a project aimed at reclaiming a dump site (progress: clean site) could lead to the recognition of lack of sensibilisation of local inhabitants (progress: awareness), refocusing the effort to promote circular economies (progress: local economies). Some specific challenges include:

- Capturing multi-functional benefits (both tangible and intangible) or multidimensional outcomes that are often locally specific.

- Capturing diverse perceptions and preferences on the level(s) of acceptable progress or success among stakeholders. Effects may be realised or felt differently by different communities (e.g. because of caste divide).

- Monitoring multiple parameters like local socio-environmental conditions (e.g. survival of planted trees in a particular region); and benefit sharing protocols.

- Measurement of the effectiveness of resource management.

- Understanding and acceptance of the landscape approaches across different stakeholders.

- Downscaling of global-level indicators (e.g. Aichi Biodiversity Targets, SDGs, and their indicators) is not always appropriate for the project-specific conditions.

- Upscaling of local-level indicators to regional/global levels.

- Insufficient capacity of the communities to use certain technologies needed for monitoring which may hinder their active participation.

\subsubsection{What Are Challenges, Opportunities and "Seeds of Change" in the SEPLS Context to Bring About Transformative Change?}

Challenges in bringing about transformative change lie in both "enablers" to decide on change and "actions" to implement a decision. The former allows for the latter through rendering conditions, resources, capacities, and means available for actors to make a decision to change their behaviour and then take action for change. Allowing that decisions are made and even formalised in the form of policies, plans and 
programmes, transformative change cannot happen unless these decisions are translated into action in practice. While a challenge is making timely informed decisions at individual and collective levels (including consensus building among multiple stakeholders), another big challenge is implementation of decisions to take a bold step for transformative change.

\section{Challenges in Enablers}

In the context of SEPLS, agents of change include a variety of stakeholders who manage SEPLS to derive and use multiple benefits directly or indirectly from across different sectors and levels. The case studies highlight three major types of "enablers" that allow for and instigate actions for change: (1) stakeholders' recognition or perspectives on SEPLS problems; (2) their technical and financial capacities; and (3) their authority over SEPLS management. These three types are not necessarily mutually exclusive, but often interrelated.

First, stakeholders cannot be motivated to change direction or go beyond business as usual without knowing a problem with current practices of using and managing SEPLS. Their awareness of problems in question, such as land degradation, water pollution, and biodiversity loss, is a critical first step in many cases to move towards a more sustainable society. Yet, as discussed above (see Sect. 13.1.2), it is not easy to comprehend the problem exactly and evaluate any progress of change due to the complexity of SEPLS. The SEPLS problems extend to multiple scales (e.g. spatial, and temporal) and levels (e.g. local, sub-national, national, regional, and international), while entailing multiple and often competing values, perspectives, and objectives that cut across different sectors. Furthermore, problems stem from non-linear and dynamic processes of human-nature interactions, involving highlevel uncertainties.

Given the complex and interlinked nature of SEPLS problems, stakeholders often fail to have a whole picture of SEPLS and recognise the compounding and multi-dimensional effects of their own practices on SEPLS sustainability from their standpoints. Urban dwellers are likely to have fewer chances to become aware of what is going on to maintain the hinterland, while rural-urban migrants may lose their metaphysical connections to landscapes along with their decreased physical contact with natural environments. Local practitioners directly engaging in SEPLS management may not necessarily recognise long-term effects of their practices, and even if their efforts would bring about transformative change in the long run, they may become easily reluctant to continue without demonstrable, short-term success within their sight or any interventions to continuously support and encourage such practices.

Secondly, also related to these cognitive aspects, technical and financial capacities of stakeholders can make them better prepared to make a sound decision on SEPLS management, but inadequacy or imbalance of such capacities often hampers well-informed and equitable decision-making. SEPLS management technically requires interdisciplinary knowledge on SEPLS involving social, cultural, ecological and economic dimensions, but such knowledge is neither necessarily available nor accessible to all stakeholders. As the case studies show, various kinds of technical 
and financial assistance have been offered to increase stakeholders' capacities, ranging from introduction to management models (e.g. supply chain, and multistakeholder collaboration), provision of monitoring and evaluation tools, and promotion of awareness raising and public relations to education and training. In recent years, these supports have increasingly attended to continuous and dynamic humannature interactions within SEPLS. Yet, again as discussed above (see Sect. 13.1.2), interdisciplinary and transdisciplinary knowledge, particularly integrating local and traditional knowledge, is still limitedly available in our society to comprehensively understand SEPLS and adequately evaluate and monitor progress in SEPLS management.

Moreover, these capacity development opportunities are not accessible to all. In particular, the opportunities are not always given to those who are most vulnerable to changes in SEPLS and those who have challenges in having sufficient resources (e.g. time, money, and energy) to address SEPLS problems. Given the contextdependent nature of SEPLS management, participatory and bottom-up approaches have been called for to mobilise and enhance local capacities (e.g. micro-enterprises, and community-based management). In many cases with fragile conditions of national finance, however, political attention is not fully given to finances to support such local and small-scale activities. This is attributed partly to the challenges in recognising the interlinkages between local problems and broader social and ecological impacts and implications of SEPLS management.

Thirdly, authority over SEPLS management is often inequitably granted or unclearly defined to make a decision to move towards a sustainable transition. Stakeholders can justify and legitimise decisions on SEPLS management if authority is given to them to do so, but if not, they can hardly pursue change rightfully. Usually different kinds of authority are granted to different stakeholders as legitimate power to use and manage SEPLS, but power asymmetries exist much in relation to disproportionate technical and financial capacities among stakeholders. For instance, the case of Montespertoli town in Italy points to weaker power of small farmers to control wheat prices compared to large industrialised commercial entities along the supply chain (Chap. 6). With the intervention through the multistakeholder efforts, more equitable producer-consumer chains have developed to a certain extent, but otherwise the economic power structure could have been risking wheat biodiversity, amplifying social inequity and further depriving farmers of authority over SEPLS management.

Furthermore, it is sometimes difficult to clearly define rights, roles and responsibilities of stakeholders in managing SEPLS where human and non-human components dynamically interact over time and space. Given the constantly changing contexts and conditions of SEPLS, stakeholders need to repeatedly assert, recreate and exercise their authorities to legitimate their decisions, although such attempts are not always successful (Ahlborg and Nightingale 2018; Sikor and Lund 2009). Dominant power in place (e.g. economic, and political) often supersedes even legislation that encapsulates authorisation over access to and use of natural resources among stakeholders. This leads to de-facto immiseration of the legally-protected constituents of society in some cases (Chap. 10) while contributing to continued 
conventional practices, for instance, through allied opposition against legal change in other cases (Ribot 2009).

To make things worse, all the above three major challenges in enablers (i.e. perceptions, capacities and authorities) can sometimes interplay viciously, serving as a binding barrier to a just and sound decision-making process for transformative change. It is often the case that short and narrow views are dominant among decision-makers who have larger capacities and stronger power to authorise use and management of SEPLS as well as access to resources. Political attention, if it is skewed towards monetary or GDP-based wealth metrics, may foster the vested interests of big business, for instance, for the sake of tax revenues or myopic economic growth. It can thus easily ignore or underestimate local and traditional knowledge and cultural practices that are valuable for SEPLS management but not directly measured with monetary values, consequently hindering transformative change. As such, despite the great potential of political will to make transformative change happen, policymakers and other decision-makers with these perspectives tend to prefer remaining with the status quo and not making a leap forward in fear of slowing or deviating from economic growth.

\section{Challenges in Actions}

In the context of SEPLS where decision-making occurs across multiple levels (e.g. local, regional, national, and international) and scales (e.g. spatial, temporal, and jurisdictional), decision-makers may not necessarily be identical with actors who take action on what has been decided. In fact, even when a decision is legitimised and formalised by authorities as legislation or policy, decision-makers most often need to delegate various tasks to others for enforcement and implementation. Such circumstances require alignment of different needs and interests as well as consolidation of different capacities among stakeholders to effectively turn a decision into action. However, divergent levels of commitment to the decision are almost inevitable across different stakeholders who have multiple and often competing needs, interests, views and objectives to manage SEPLS. Likewise, varied levels of engagement and participation in activities based on the decision are often unavoidable given the different technical and financial capacities among stakeholders, though through collaboration they can complement each other to fill a gap in capacities.

In particular, local stakeholders' participation and engagement are indispensable for making change happen, given that they steward SEPLS on the ground in most cases. Nevertheless, they often cannot afford to do so on their own due to their limited technical and financial capacities, even if granted nominal authority over SEPLS management. At the same time, they can hardly dare to be fully committed to a decision that might be associated with high-level uncertainties, being most vulnerable to SEPLS changes in many cases. Most often it is indeed hard to make a bold decision and take a brave leap forward. The case study of the Colombian Pacific region offers a prime example of the predicament of local stakeholders (Chap. 10). Even with the legislation established by the national authority to recognise and protect their collective ownership rights to the lands and to promote their social and economic development, Afro-descendant communities have continuously 
suffered from illegal exploitation by unauthorised but armed groups, whereas local stakeholders including local authorities had limited technical and financial capacities. In particular, public funds appeared to be insufficient in implementing and monitoring local management plans through local authorities in this case.

\section{Opportunities in SEPLS for Transformative Change}

If viewed from the flip side, most of the above challenges can be opportunities for transformative change. In the context of SEPLS, diverse stakeholders have been brought together to decide and act on SEPLS management, taking advantage of knowledge and practices that have been locally accumulated through long-term human-nature interactions. The case studies show the potential of SEPLS to lead to transformative change particularly in regard to the following aspects of SEPLS: "diversity", "wisdoms", and "integrity".

- Diversity: Involvement of diverse stakeholders tends to yield mismatches, discrepancies or even conflicts between them in terms of their interests, needs, perspectives and objectives. At the same time, however, such "diversity" renders diverse enablers (e.g. knowledge, financial resources, and alternative means and tools) available to help address shocks, uncertainties and non-linear changes. This as such helps to manage risks and facilitates ecosystem-based adaptation to environmental changes including climate change and pandemics.

- Wisdoms: Local stakeholders are often most vulnerable to SEPLS changes but have accumulated and enriched practical and experiential knowledge on SEPLS management, nurturing local and indigenous knowledge. Their knowledge has been embedded in local contexts as "wisdoms" for their survival but could be applied and extended through bottom-up approaches (e.g. local empowerment, and peer-learning) to promote a more sustainable and resilient society.

- Integrity: Dynamic interactions between human and non-human components across different levels and scales disallow a one-sided solution to address multiple dimensions of a SEPLS problem. Yet, vertically and horizontally "integrated" strategies help increase synergies and minimise trade-offs between different elements of SEPLS to effectively meet multiple needs for improved humannature relationships. This can be made through mobilising diverse resources and capacities of stakeholders and facilitating multi-stakeholder collaboration with involvement of youths, women and the elderly.

\section{Moving from Seeds of Change to Transformative Change}

Most of the cases exemplify "seeds of change" within which transformative change has been emerging as observed in some positive outcomes for local communities or diffusive effects to surrounding or different regions (e.g. replication of good practices), but is yet to fully happen. Importantly, some niche innovations (e.g. sustainable farming practices, equitable supply chains, and buy-in of business and industries in recycling) have been already put in place largely at the local and regional levels in most of the cases in this volume. These innovations, however, are still in 'incubation rooms' somewhat waiting for radical changes (Geels 2005, p. 684). To take a further step in bringing about transformative change, a more 
systemic approach would be required to address deeper leverage points (i.e. the places for interventions in a system, which are deeply rooted in the causes of unsustainability) rather than shallow ones (i.e. the places for easily implementable interventions) (Abson et al. 2017).

In connection to deeper interventions, the findings from the case studies suggest that a more strategic approach to SEPLS management would help facilitate turning "seeds of change" into transformative change, particularly in the following respects: (1) concept of values or mindset; (2) governing processes; and (3) governing outcomes. The first point is relevant to the "intent", one of the system characteristics of SEPLS in the realm of deep intervention, underpinning values, goals and worldviews of actors that shape the direction of change. The second and third ones are relevant to the "designing" characteristic of SEPLS also in the realm of deep interventions, which determines social structures and institutions to manage shallow interventions (also see Chap. 1).

Concept of Values or Mindset First, to break the status quo, stakeholders' conception of values or their mindset should be diverted from what is skewed to economic growth based on the currently entrenched metrics such as GDP to what is extended to multiple facets of well-being. As the case studies elucidate, values of SEPLS are reciprocal across different domains of SEPLS (e.g. circular economies) rather than linearly cumulative, entailing multiple benefits for well-being (e.g. health, and quality of life) (e.g. Chaps. 2, 3, 5, 6, 7 and 12). This can be demonstrated in several ways as follows:

- Communicating multi-dimensional values of a certain product to its consumers would help change their consumption behaviour (e.g. Chaps. 6 and 7). It may also effectively promote chains of changes by taking advantage of existing supply chains but ensuring equitable sharing and distribution of benefits.

- Innovative educational and capacity development approaches would help people to recognise themselves as agents of change through identifying their rights, power and contexts particularly in connection with their individual or collective emotional links to the natural environment (e.g. ethno-education, visioning exercise, and peer experiential learning, for instance, demonstrated in Chaps. 8 and 10), instead of top-down or one-way knowledge transfer. They can facilitate behavioural changes and foster better relationships between humans and natural environments.

- Efforts to raise awareness of biodiversity at every chance, for instance, through daily life, social media and campaigns, would help promote biodiversity mainstreaming among diverse stakeholders. The target audience would range from lay people to politicians for mainstreaming in policymaking and implementation as well as from youths to the elderly for inter-generational equity and empowerment of future generations.

- Multi-stakeholder and participatory learning processes would help identify innovative means for more sustainable human-nature relationships (often bringing in 
various types of knowledge including local, indigenous and scientific ones) and scale up good practices (e.g. Chaps. 7 and 9). For example, groups of farmers experiment with sustainable methods for which field days and discussions are organised with involvement of various stakeholders to scale it up for the wider community.

Governing Processes Secondly, governing processes should be inclusive and participatory where all stakeholders can have a say in what SEPLS could be sought after and how SEPLS should be achieved and managed, allowing for inclusion of multiple values held by diverse stakeholders who act on decisions as agents of change. At the same time, the processes should ensure that stakeholders finally legitimise the decisions made in the processes for authorised implementation and enforcement to make transformative change happen. To do so, it is crucial to exploit all opportunities from across different levels, scales and sectors of SEPLS management all along with the participatory governing processes including policymaking and implementation. This would enhance communications, facilitate mutual learning and help address inequalities between all stakeholders. It would further allow for better chances for effective and equitable multi-stakeholder collaboration and promote ownership of the SEPLS by the local communities. Some examples include the following, but all together would facilitate the processes to incite a mass movement towards a sustainable society:

- A hybrid of top-down and bottom-up approaches to policymaking would contextualise local problems in policies and vice versa and render longer-lasting effects through fostering ownership of decision outcomes among multiple stakeholders (e.g. Chaps. 7 and 8).

- With a view to the governing process including policymaking and implementation as a learning opportunity, involving government authorities from the early stages, possibly from multiple levels, would facilitate political buy-in and ensure authorisation of decision-making outcomes (e.g. Chaps. 7 and 12).

- Through policy cycles as learning processes, good practices can be scaled up and out and deepened to ensure knowledge-policy-practice linkages. Inputs into policy cycles can be made, for instance, through interactive workshops among stakeholders (particularly involving policymakers) and brief and easy-to-digest publications for policymakers.

- Along with the processes, facilitators serve as key agents of change to identify a common language for conversation, create communication channels, mobilise technical and financial capacities, and secure representation among all the stakeholders (e.g. Chaps. 2, 3, 4, 5, 6 and 9).

Governing Outcomes Finally, governing outcomes resulting from the governing processes should build in reciprocal, equitable and interactive connections between human and non-human entities. Governing outcomes should not be static but rather dynamic to flexibly adapt to change when and where appropriate, but a certain 
governing structure could be aimed for to make governing efforts sustainable. Within the governing structure, rights, roles and responsibilities of stakeholders should be clearly defined with transparency. Some ways forward include:

- To take advantage of scientific evidence as well as practical lessons learnt from experiences, science-policy-practice linkages should be integrated in the governing structure. For this purpose, networks of diverse actors including indigenous peoples and local communities may pragmatically serve to transmit traditional knowledge and give voices to those who manage SEPLS on the ground.

- Equitable production and supply chains should be entailed in the structure finally to facilitate behavioural change of consumer (i.e. end users) for sustainability.

- The working of the governance system should be accountable and transparent to all the stakeholders. This allows them to continuously legitimate and justify SEPLS management, knowing who exercises what authorities to provide what benefits to whom. It would also help to identify opportunities to improve and enhance multi-stakeholder collaboration to pursue transformative change.

\subsection{Conclusion}

Bringing about transformative change towards sustainability in the SEPLS context requires pragmatic approaches to ensuring the well-being needs of the community along with the integrity and diversity of the ecosystems and resources therein. The bottom line is that the priorities of conservation, restoration, sustainable use and equitable sharing of benefits arising from SEPLS need to be integrated into actions by different actors operating in the SEPLS who are motivated to deliberate and choose sustainable pathways. The motivations of those actors are essential for transformative change as they drive such change endogenously and sustainably. These motivations could be triggered by interventions such as innovative educational and capacity development pedagogies that instil a sense of place and pride in engaging in sustainable action; and participatory and interdisciplinary approaches to identify challenges and solutions in managing the SEPLS to enhance a sense of ownership and follow-up actions amongst all actors. Such (deep) interventions can be designed to bring about a systemic, society-wide change but would take a longer time than immediate fixes to show results.

Other interventions that have impacts include, for instance, policies that support sustainable production and consumption, reduce waste, promote recycling, invest in conservation of crop diversity or ecosystem services amongst others. These interventions are not trivial as they help make endogenous SEPLS management more persistent and legitimate. As the case studies show, the SEPLS management exemplifies the "seeds of change" manifesting niche innovations with great potential to lead to a regime shift in bringing about transformative change. Depending on the contexts, requirements and information at hand, various intervention models have been explored across different sites. These models are highly context-dependent and 
can be strengthened through the collaborative processes where the stakeholders engage and negotiate in identifying optimal solutions amongst different and sometimes competing needs and interests.

While distinct in their approaches depending on specific contexts and circumstances, the case studies of SEPLS management also underscore several common principles, including the following:

- Endogenously driven actions based on value pluralism: Actions need to be endogenously driven by different stakeholders at the community level who proactively design their plan of action and make and implement decisions to address their needs and interests. In determining their decisions and actions, all stakeholders' perspectives should be respected and the plurality of values should be acknowledged in relation to the use and management of resources as well as the development pathways that exist among the actors.

- Systemic and transdisciplinary approaches to fostering niche innovations: A systemic approach should be taken to foster niche innovations in managing SEPLS and governing all resources within the landscape and seascape. This requires creative integration of different knowledge systems to arrive at sustainable solutions and therefore the expertise of people with a diversity of backgrounds (farming, education, capacity development, conservation, value addition, etc.). In particular, the approach needs to be reflected in the implementation of national policies to ensure coherence between multiple policy objectives as they interact so that they are mutually supportive across different sectors.

- Equitable authority over SEPLS resources: In governing the SEPLS management, authorities over access to and use of natural resources should be equitably granted and clearly defined for policymaking and implementation to move towards sustainable transition. In this regard, being respectful to customary rights and local priorities is a necessary condition to ensure that both social and ecological goals are achieved.

- Coordinated multi-level networking through peer learning: To allow for a systemic approach, networking between actors at multiple levels and scales is important, and often benefits from having a strong facilitator to convene and mobilise the community towards envisioning and acting on a common agenda. Related to networking is the importance of fostering peer learning within and between communities and other actors in and beyond SEPLS. It enables more effective sharing of learning experiences regarding contextually replicable solutions towards sustainability.

- Iterative participatory and inclusive assessments for strategically steering transitions: Developing a clear strategy is needed to monitor, evaluate and adaptively manage changes towards desired outcomes so as to take steady steps for sustainable transitions. The process for this should be participatory, inclusive and respectful with clear boundaries that enable systematic assessments and course corrections.

It is noteworthy that these principles, distilled from actions on the ground, speak directly to several conceptual dimensions relating to transformative change that are 
being discussed in mainstream literature. The case studies along with this synthesis make the point that experiences from the ground can inform policymaking processes to enable better policy design and more effective implementation to meet policy objectives. Furthermore, we make a strong argument that transformative change is a concept that is already being explored on the ground, and even if it may be variously interpreted depending on socio-ecological contexts, there are some clear principles that emerge and can inform its uptake at multiple levels of implementation.

Revisiting the concept then, transformative change in the SEPLS context may be conceptualised as a radical change that is built on niche innovations of local initiatives and fostered through adaptive co-management and use of a mosaic of ecosystems towards enabling socio-ecological resilience. The process of change is endogenously led and inclusive of the plural values held by different stakeholders in the system, whereas deliberations and negotiations amongst different stakeholders are pursued. Through a systemic approach that also facilitates integration across different levels and sectors, it promotes multiple agendas to fundamentally address local needs and interests but extends to achieving global goals-conservation, restoration and sustainable use of biodiversity and ecosystems, innovative production and governance practices, equitable transactions of natural resources among actors, creative integration of multiple worldviews and knowledge systems through peer learning, continuous monitoring and evaluation of progress, and multistakeholder partnerships for collaborative actions.

\section{References}

Abson, D. J., Fischer, J., Leventon, J., Newig, J., Schomerus, T., Vilsmaier, U., von Wehrden, H., Abernethy, P., Ives, C. D., Jager, N. W., \& Lang, D. J. (2017). Leverage points for sustainability transformation. Ambio, 46, 30-39.

Ahlborg, H., \& Nightingale, A. J. (2018). Theorizing power in political ecology: The "where" of power in resource governance projects. Journal of Political Ecology, 25, 381-401.

Bergamini, N., Dunbar, W., Eyzaguirre, P., Ichikawa, K., Matsumoto, I., Mijatovic, D., Morimoto, Y., Remple, N., Salvemini, D., Suzuki, W., \& Vernooy, R. (2014). Toolkit for the indicators of resilience in socio-ecological production landscapes and seascapes (SEPLS). Rome: UNU-IAS; Biodiversity International.

Geels, F. W. (2005). Processes and patterns in transitions and system innovations: Refining the co-evolutionary multi-level perspective. Technological Forecasting and Social Change, 72, 681-696.

IPBES. (2019). Global assessment report on biodiversity and ecosystem services of the Intergovernmental Science-Policy Platform on Biodiversity and Ecosystem Services. Bonn: IPBES Secretariat.

Ribot, J. C. (2009). Authority over forests: Empowerment and subordination in Senegal's democratic decentralization. Development and Change, 40, 105-129.

Sikor, T., \& Lund, C. (2009). Access and property: A question of power and authority. Development and Change, 40, 1-22.

SOAS. (2013). Project planning and management-C134 unit ten: Monitoring and evaluation. 
UNU-IAS \& IGES. (2019). Understanding the multiple values associated with sustainable use in socio-ecological production landscapes and seascapes (Satoyama initiative thematic review) (Vol. 5). Tokyo: United Nations University Institute for the Advanced Study of Sustainability.

The opinions expressed in this chapter are those of the author(s) and do not necessarily reflect the views of UNU-IAS, its Board of Directors, or the countries they represent.

Open Access This chapter is licenced under the terms of the Creative Commons Attribution 3.0 IGO Licence (https://creativecommons.org/licenses/by/3.0/igo/), which permits use, sharing, adaptation, distribution and reproduction in any medium or format, as long as you give appropriate credit to UNU-IAS, provide a link to the Creative Commons licence and indicate if changes were made.

The use of the UNU-IAS name and logo, shall be subject to a separate written licence agreement between UNU-IAS and the user and is not authorised as part of this CC BY 3.0 IGO licence. Note that the link provided above includes additional terms and conditions of the licence.

The images or other third party material in this chapter are included in the chapter's Creative Commons licence, unless indicated otherwise in a credit line to the material. If material is not included in the chapter's Creative Commons licence and your intended use is not permitted by statutory regulation, or exceeds the permitted use, you will need to obtain permission directly from the copyright holder.

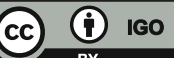

